\title{
Advanced Students’ L1 and L2 Mastery of Lexical Fields of Near Synonyms
}

\author{
Monica Karlsson ${ }^{1, *}$ \\ ${ }^{1}$ School of Teacher Education, Halmstad University, Sweden \\ *Correspondence: School of Teacher Education, Halmstad University, Sweden. E-mail: mica.karlsson@glocalnet.net
}

Received: July 11, 2014

doi:10.5430/wjel.v4n3p1
Accepted: July 22, $2014 \quad$ Online Published: August 21, 2014

URL: http://dx.doi.org/10.5430/wjel.v4n3p1

\begin{abstract}
In the present investigation, 15 first-term university students were faced with eight fields of near synonyms in English (L2) and Swedish (L1) respectively and asked to pair up each item with its correct definition. Both the synsets as a whole and the items within each synonym set were of varying frequency. The investigation thus addresses the following research question:

In quantitative and qualitative terms, how well do advanced students master lexical fields of near synonyms on a whole as well as the respective items in each synonym set in their L2 as compared to their L1?
\end{abstract}

Results show that while most students have a relatively poor knowledge of L2 synsets as compared to in their L1, the knowledge they do possess appears to be strongly frequency-based.

Keywords: L1 versus L2; lexical field; near synonyms

\section{Introduction}

"As the fluency of advanced language students increases, so too does the number of vocabulary errors they generate, both in speaking and in writing. Some of these errors are the result of first language transfer", such as errors with false cognates, "but the majority are interlingual, i.e. they reflect confusion between and among lexical items in the second language itself”. Furthermore, all "vocabulary errors manifest one or more kinds of dissonance between the word and its context”. (Martin, 1984:130) There are four types of dissonances that appear to be especially common in the language of advanced learners: stylistic (*dunk (instead of for example dip) the chicken pieces in the beaten egg mixture); syntactic (*the author purports that tobacco is harmful (the verb purport requiring a non-human subject)); collocational (*I used to be a large smoker (instead of a heavy smoker)) and semantic (*I was badly damaged in the accident (instead of injured which is used for animate objects)) (Martin, 1984:130). It is the latter of these types which is in focus here, more specifically the present study will deal with lexical fields of near synonyms, also referred to as synonym sets or synsets.

\section{Theoretical Anchorage and Previous Research}

\subsection{L1 and L2 Vocabulary Depth}

In the research literature there are two main ways of conceptualizing vocabulary depth. On the one hand, words may be seen to be organized into lexical networks. Researchers approaching vocabulary depth in this way focus on how words are stored in learners' mental lexicons in relation to each other. On the other hand, words may be considered from a component perspective in which not only semantic characteristics, but also a word's orthographic, phonological, morphological, syntactic, collocational and pragmatic features are taken into account. It is only the former type which will be considered here.

Within a connectionist framework, whether it is concerned with an L1 or an L2, a developing vocabulary network, i.e. a network in which some items are acquired whereas others are lost, is described in terms of the strengthening and 
weakening of neural links or so called network nodes. Furthermore, Albrechtsen, Haastrup \& Henriksen (2008:22) claim that

[t]he many lexical entries in our L1 mental lexicon are not stored randomly, but are structured in a well-organized web with connections or pathways between the words; a structural system that enables us to retrieve words rapidly and with ease, because the access routes in the lexical store are varied and well-established

and wonder

[c]an the same be said about foreign language learners' mental lexicon at different stages of their interlanguage development. By nature, the L2 learner has had less exposure to the target language; so, one would naturally expect the L2 lexicon to differ from the L1 lexicon - not only in relation to size, but also in relation to the structural properties of the word store. But how different is the L2 lexicon?

Trying to find out about differences between L1 and L2 vocabulary networks, researchers have engaged learners in so called vocabulary association tests of which there are two main types: productive association tests and receptive association tests. In the former case subjects are most commonly offered prompt words and asked to say/write the first word that springs to mind (Söderman, 1993; Singleton, 1999; Wolter, 2001; Namei, 2002 and 2004). Productive association tests can thus be said to deal primarily with the types of links seen in the mental lexicon. In receptive association tests informants are most commonly given a stimulus word (e.g. edit) and asked to indicate to which items in a set of words (e.g. arithmetic, film, pole, publishing, revise, risk, surface and text) they believe it is linked (Read, 1993). Thus in such cases, researchers focus on the number of links and/or the density of links.

Interesting results have sprung from both types of testing. As for productive association testing, conclusions have been drawn in four main areas. Firstly, form-related responses have been contrasted with meaning-related responses and there are clear indications that both L1 and L2 beginners give more so called clang responses than adult L1 learners and advanced L2 learners. Young L1 and L2 learners are hence much more likely to give a word like land when offered the stimulus word hand, while adult L1 learners and advanced L2 learners are more likely to produce the word finger when faced with the same prompt word. (Meara, 1978; Piper \& Leicester, 1980; Cohen \& Aphek, 1981; Söderman, 1993; Singleton, 1999; Wolter, 2001) Secondly, syntagmatic responses have been compared with paradigmatic responses. Most research in this area shows that whereas beginners (in L1 as well as in L2) tend to offer words that are linked collocationally to the stimulus word, such as the word butter as a response to the prompt word bread, more advanced learners (again both in L1 and in L2) give words that are linked predominately in hierarchical ways to the prompt word, such as the word animal as a response to the stimulus word $d o g$. Thirdly, prototypical responses (which can be either syntagmatic or paradigmatic), i.e. answers that a majority of informants tend to give to certain prompt words (Singleton, 1999; Wilks \& Meara, 2002; Murphy, 2003) (e.g. ice, hot, freezing and blue as responses to the stimulus word cold) have been contrasted with more infrequent responses (e.g. shoulder, hankie and dreary as responses to cold) (Albrechtsen et al., 2008:33). Results of such studies show that native speakers generally produce many more prototypical responses than do non-native speakers and that advanced L2 learners produce more such responses than do low-proficiency L2 learners. This is especially interesting in view of the fact that prototypical associative links appear to "play a central role in the structuring of the mental lexicon, perhaps functioning as bridges or pointers between different parts of the net" (Albrechtsen et al., 2008:34). Lastly, the frequency of the response word has been investigated. Research here shows that high-achievers in an L2 are not only more likely to offer prototypical answers than low-achievers as described above, but are also more likely to produce more low-frequent responses than low-achievers (e.g. Namei, 2002 and 2004). From the above, it is evident that there is a difference in the number of form-related/meaning-related, syntagmatic/paradigmatic, prototypical/non-prototypical and high-frequent/lowfrequent responses given between on the one hand L1 learners and L2 learners and on the other hand advanced L2 learners and low-proficiency L2 learners. Nevertheless, Albrechtsen et al. (2008:35) emphasise that

[t]he whole lexicon as such cannot be described as either form-driven versus meaning-driven or syntagmatically versus paradigmatically structured. The structural properties of the lexicon will rather be determined by the language learner's degree of knowledge of the individual lexical item. In the initial phases of learning, the semantic specifications in the lexical entry are relatively weak, and we thus find that formal factors play a significant role. When dealing with less familiar vocabulary items with weaker semantic specifications mapped onto the word the more advanced learner may still rely more on the form-driven, phonological information in the lexical entry. With increased word knowledge, the words become more and more meaning-driven. Paradigmatic or syntagmatic response types will be given, but the response type will be related to the degree of word knowledge. 
Receptive association testing, focusing on, as mentioned above, the number and density of word links, has also produced some interesting results that help shed light on differences in the structure of the L1 and L2 lexical network. In Greidanus, Beks \& Wakely (2005), for instance, native speakers clearly outperformed L2 learners in identifying association links between words. Moreover, Greidanus \& Nienhuis (2001) and Greidanus, Bogaards, Van Der Linden, Nienhuis \& De Wolf (2004) could show that the more advanced the L2 learners were, the more links they could identify. This difference was especially pronounced with high-frequency words. Albrechtsen et al. (2008:38) conclude that

[n]ative speakers are able to identify a significantly higher proportion of network links than are L2 learners. In other words, the results indicate that the mental lexicon of a language learner is qualitatively different; that is, less dense than that of a native speaker. An implication of this may be that an L2 learner's retrieval paths are different as to the number of paths and their length; a fact that may well affect his ability to access words efficiently in L2 reception.

As for items belonging to synonym sets, there are many different kinds of relations that can be seen. Accordingly, this affects the errors made by L2 learners. One common error is to use a semantically restricted term when a more general one should be used. This is exemplified in *I have to rectify (instead of correct) my younger brothers all the time. Rectify is restricted in the sense that it is only used with abstract nouns that denote something bad or wrong, i.e. you can rectify abuses, errors and mistakes, but not brothers. Correct, on the other hand, is a word that can be used to cover a wide range of actions. You can, for instance, correct a person, papers or your watch. There are other near synonyms in this field that are also restricted in their use, all of which therefore are hyponyms of the superordinate term correct. For example, one can reform but not emend a person and one can remedy but not redress a situation. This thus means that "hyponyms cannot often be used in all the contexts open to the superordinate. By the same token, co-hyponyms (the entire set of specialised items related to a superordinate) may rarely be used interchangeably” (Martin, 1984:133). In other sets, different factors are involved. As already exemplified in the previous paragraph with injured versus damaged, the semantic distinction may, for example, depend on whether the subject is animate or inanimate. It may also have to do with whether one is referring to something physical or non-physical. Fluctuate and wobble may be used to illustrate this distinction. Whereas the former verb is limited to non-physical subjects, the latter generally only goes with physical ones. This is the reason why the sentence *The air holes (of the clay sculpture) are filled, which may cause the head to fluctuate later on is semantically incorrect. The near synonyms spectator and onlooker denote yet another semantic distinction. While spectator has the connotation that your presence was planned, onlooker does not. It would therefore be incorrect to say *One of the spectators was hurt in the accident. Near synonyms in a lexical set may also be distinguished from each other by intensity. In the following synset, in which surprise is the superordinate, there is a clear increase in intensity: surprise, astonish, amaze, astound and flabbergast, flabbergast being the strongest of all the items. The choice of synonyms can also reflect the speaker's attitude. While the verbs persevere and enjoy denote approbation, persist and be subjected to involve negative feelings. Both continue and receive, on the other hand, are quite neutral in this respect. Thus, depending on the choice of verb in a sentence like This region enjoys/receives/is subjected to thirty inches of rain a year, different speaker attitudes may be denoted. Other semantic relations between near synonyms are, for example, state versus event (e.g. exist (this trend exists on many college campuses) and happen (*this trend happens on many college campuses)) and volitional versus non-volitional (e.g. deter versus keep (cf. the drug deterred/kept him from falling asleep). Many items in synonym sets also involve more than one semantic contrast. (Martin, 1984:133-134) In Rudzka, Channel, Pudseys \& Ostyn (1981), for example, a more detailed analysis than a mere increase in intensity is given of the synonym set surprise, astonish, amaze, astound and flabbergast discussed above:

Table 1. An Example of an Analysis of a Lexical Field of Near Synonyms (Rudzka et al., 1981)

\begin{tabular}{lccccc}
\hline & $\begin{array}{c}\text { Affect with } \\
\text { wonder }\end{array}$ & $\begin{array}{c}\text { Because } \\
\text { unexpected }\end{array}$ & $\begin{array}{c}\text { Because difficult } \\
\text { to believe }\end{array}$ & $\begin{array}{c}\text { So as to cause } \\
\text { confusion }\end{array}$ & $\begin{array}{c}\text { So as to leave one } \\
\text { helpless to act or think }\end{array}$ \\
\hline surprise & + & + & & & \\
astonish & + & & + & + & \\
amaze & + & & & & + \\
astound & + & & & & + \\
flabbergast & + & & & & \\
\hline
\end{tabular}

Another example is offered in Martin (1984:134) involving the near synonyms misplace and mislay. While mislay only may mean that you do it by accident, misplace may mean that you do it either by accident or by an act of will. 
Additionally, whereas one can only mislay physical objects such as one's documents, one can misplace physical objects as well as abstractions such as one's trust.

Research on L2 learners' mastery of lexical fields of near synonyms is scanty. Moreover, some of the research focusing on pedagogical approaches appears to have led to conflicting conclusions. While some researchers believe that it may be beneficial to L2 learners to encounter and learn words in semantic fields (e.g. Nagy, 1989; Holmegaard, 2000), one of which is synsets, others believe that this approach may severely interfere with the learning of the items involved (e.g. McGeoch \& McDonald, 1931 which investigated L1 mastery, see also Tinkham, 1993 and Waring, 1997 for other semantic relations than synsets). Martin (1984:130) in fact goes so far as to say that "the teaching of vocabulary via glosses or "synonyms" in the target language is a prime culprit in the production of unhappy lexical choices among advanced students". Only more research in the area will be able to determine which view is correct.

\subsection{The Frequency Effect of Near Synonyms in Lexical Fields}

A substantial amount of research has shown that native speakers have good intuitions about the frequency of different vocabulary items (Richards, 1974; Ringeling, 1984; Arnaud, 1989), both single words and multi-word items (Backman, 1978). More and more research shows that frequency also affects how words are processed in the mental lexicon of non-native speakers, although it is unclear whether L2 intuition about frequency is based on the L2 words alone or if it is based on the frequency of L1 translation equivalents (Arnaud, 1989). In Schmitt \& Dunham (1999), it was investigated to what extent this holds true for lexical fields of near synonyms such as appliance-contrivance-device-gadget-machine, glisten-shimmer-sparkle-shine-twinkle and awful-bad-dreadfulghastly-terrible. Thus, their results are of great importance to the present investigation and will be discussed in the paragraphs that follow.

In Schmitt \& Dunham's main study 5 groups of non-native speakers of English were included, forming a heterogeneous set of informants both in terms of educational background and mother tongue (e.g. Arabic, Czech, German, Spanish). A group of native speakers of various educational levels were also included.

To ensure the accuracy of the frequencies of the test items, Schmitt \& Dunham used two corpora when selecting the lexical sets: the BNC and the COBUILD Bank of English Corpus. Only sets of near synonyms where the two corpora agreed as to the relative frequency of the test items in each field were included. Also sets for which the frequencies of the individual test items agreed the best in the two corpora were prioritised. Thus 12 lexical sets were finally selected (3 noun sets, 3 verb sets and 3 adjective sets). For each set, 5 near synonyms were chosen, all of which were similar in length. Moreover, one of the items in each set was picked to be the 'anchor word', against which the other four test items were to be rated. For example, in the set exemplified in (1), the word catastrophe was considered the anchor word. If an informant thought that disaster was ten times as frequent as catastrophe he/she was asked to write 10 after disaster. Similarly, if a subject thought that, for instance, calamity was one third as frequent as catastrophe, he/she was to write $1 / 3$ after calamity. If the anchor word happened to be unknown, the subject was to assign the anchor role to another of the items in the set. A pilot study indicated that this was a useful approach.

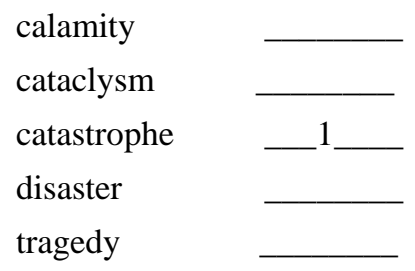

The informants were then asked to make a number of frequency judgements of increasing level of difficulty. The first task was to pick out the core word, i.e. the most central word in terms of frequency. (Note that the core word is here not the same as anchor word, although for two of the lexical sets these items coincided.) The results showed that the native speakers were able to pick out the core word $77 \%$ of the time, the accuracy rate being even higher, $85 \%$, when the two lexical sets where the core word and the anchor word coincided were excluded. For the sets that were completed by the L2 learners, the corresponding percentages were $71 \%$ and $79 \%$ respectively.

The second and more difficult task was to rank the items in each lexical set according their frequency in relation to each other. As expected, the native speaker did better than the non-native speakers. However, even though the native speakers outperformed the L2 speakers, their scores were quite low, showing an accuracy percentage of only 10\% (22\% with one transposition).

In the third task, the most difficult one, the informants were asked to judge the absolute frequencies of the test items, i.e. exactly how often each item occurs in the English language. Here the native speakers' answers showed that they did 
not form a homogeneous group, the more well-educated subjects scoring higher than those with less education. Furthermore, the results of the more well-educated non-natives in relation to the group of native speakers having little education were rather unexpected, the former subjects actually achieving higher scores than the latter ones.

From the tasks described above, Schmitt \& Dunham drew the conclusions that L2 learners who have reached the same level of proficiency as native speakers are almost as good at picking out the core word and rating the absolute frequencies of near synonyms as native speakers.

\subsection{L2 Students’ Mastery of Near Synonyms}

In Haastrup \& Henriksen’s (2000) longitudinal study spanning over three years, young Danish L2 learners’ acquisition of lexical sets in English was investigated. (Since Danish and Swedish are closely related languages, the study is particularly interesting to present investigation.) By studying how L2 learners' receptive knowledge of adjectives of emotion (such as afraid, angry, happy and sad) and physical dimension (in subsets such as large, small and wide) develops in relation to other near synonyms in the same lexical field, the researchers were aiming at gaining insights into how L2 learners build networks since "vocabulary acquisition is more a matter of system learning than of item learning” (2000:225), ultimately adding information as to how L2 vocabulary acquisition may be enhanced. "The study rests on the assumption that learners build up semantic fields by adding terms to them as they elaborate their vocabularies by creating links between words they already know and new L2 words. During this process of network building, they continually restructure their semantic network in order to accommodate new words” (2000:221-222). More specifically, in Haastrup \& Henriksen's study, this entails “that a certain adjective such as happy finds its place in relation to other adjectives in its lexical field through a growing understanding of, for instance, paradigmatic relations” (2000:222) as antonomy (happy versus sad) synonymy (happy and thrilled) and gradation (happy versus overjoyed and delighted), all of which have proved to be especially pertinent when studying lexical fields of adjectives (Miller \& Fellbaum 1991).

The study included 17 Danish 12-year olds who, when the testing started, had been learning English for approximately one and a half years. All in all, there were three test opportunities, occurring at intervals of one year. As a reference corpus, the results of a number of native speakers, also aged 12, were collected. As already mentioned above, the study focused on two types of adjectives: those of emotion and those of physical dimension. While the latter group included items that are some of the most frequently used adjectives in the English language and thus acquired very early by native speakers, the former group included adjectives of a more abstract nature and less frequently used.

Four tasks were put together, three of which were so-called sorting tasks of increasing complexity. In the first sorting task, the subjects were given a list of adjectives from the two sets tested. Their task here was to place the adjectives in one of four categories: happy, afraid, temperature and size. In the second sorting task, adjectives of emotion were presented to the informants on cards in a decontextualised form. The subjects were faced with the task of sorting each card into one of four categories: sad, happy, angry or afraid. In the third sorting task, the learners were asked to grade 8 adjectives from the two fields of happy and afraid respectively in terms of their degrees of intensity. However, due to a mishap this task became unintentionally easier than sorting task number two and was therefore excluded from the final analysis. Lastly, in the fourth task the informants were requested to choose near-synonyms from the fields of sad, happy, angry and afraid to fit in 16 different situations. (To make it more difficult for the students, distracters were included.) The following example shows one such situation.

(2) You are alone in a house. Around midnight you hear footsteps in the hall.

You are/feel afraid.

frightened.

alarmed.

thrilled.

gloomy.

Two main research questions were addressed. Firstly, when faced with the same adjective how do learners perform on tasks involving lexical relations such as synonymy and gradation? Secondly, how does learners' knowledge develop with items in a specific lexical field? In connection with these research questions three hypotheses were put forth. The first hypothesis predicted that it would be easier for the L2 learners to make a distinction between an adjective of emotion and an adjective of physical dimension than putting a specific adjective in one of four lexical subsets that each denotes a specific basic emotion (e.g. afraid, angry, happy or sad). Synchronically, the hypothesis was confirmed for a majority of the items tested. The second hypothesis held it would be easier to ascribe the correct basic feeling of two 
items of the same lexical field than to decide differences in intensity between these two items. Lastly, the third hypothesis predicted that integrating an item into a lexical field is a slow process and that a context-based category-providing task will create a situation which will increase the speed of the process. The second and third hypotheses were both tested from a diachronic perspective. Only 2 of the 17 informants showed improvement, confirming that, as in a native language (Aitchison, 1994), network building in an L2 is indeed a difficult and incredibly slow process. The two subjects who displayed progression acquired most of the items in the happy and afraid subsets first (cheerful-chuffed-excited-glad-high-overjoyed-pleased-thrilled and alarmed-anxious-distressed -frightened-panic-stricken-petified-scared-terrified-uneasy), indicating that these subsets were easier than those of angry and sad (annoyed-cross-furious-grumpy-mad-moody-outraged and depressed-disappointed-miserable-moody -sorrowful-uneasy-upset respectively). Haastrup \& Henriksen (2000:236) mention several factors that may have affected this result. In addition to word-specific features and learner motivation, the frequency of the adjectives and transfer from the informants' mother tongue appear to have played significant roles as to which adjectives were acquired and which were not. Three of the words that seemed especially difficult to master - chuffed, furious and miserable -, the latter of two belonging to the subsets of angry and sad, all have, according to Haastrup \& Henriksen, comparatively low frequency and no formal similarity to Danish.

\section{The Present Study}

In the present investigation, 15 first-term university students were faced with eight fields of near synonyms in English (L2) and Swedish (L1) respectively and asked to pair up each item with its correct definition. (There were 12 female and 3 male students, 10 of whom were in their late teens or early 20s, 4 in their late 20s and 149 -year old.) Both the synsets as a whole and the items within each synonym set were of varying frequency. The informants were also asked to evaluate their L1 and L2 knowledge. The investigation thus addresses the following research question:

In quantitative and qualitative terms, how well do advanced students master lexical fields of near synonyms on a whole as well as the respective items in each synonym set in their L2 as compared to their L1?

Also, one native speaker, a 33-year old male studying within the Swedish educational system to become an upper secondary school teacher of English, was used as a point of reference for the L2 test.

In both languages, 40 words belonging to 8 different fields were tested. Based on the BNC and Språkbanken (a Swedish corpus), the synsets were presented to the students according to the total frequency of the items involved in each field, starting with the most frequent set (which on the English test was the lexical field of ailment, complaint, disease, disorder, illness, infirmity and sickness) and ending with the least frequent set (quaver, quiver, shiver, shudder and tremble on the English test). (Within each lexical field the items were presented randomly.) While the English test items were picked on a random basis from the booklet English synonyms and false friends (Hargevik \& Stevens, 1978), the Swedish test items were randomly chosen from a book by Hallström \& Östberg (2003) which, among other things, presents a number of lexical fields of near synonyms used in Swedish. The number of test items in each lexical field and their word class affiliation are shown in the table below. As can be seen, whereas the number of fields and the number of items tested in each field are the same in both languages, the word class in focus varies. (All the synsets are shown in Tables 6 and 7, the former presenting the English fields and the latter presenting the synsets included on the Swedish test.)

Table 2. The Distribution of the Number of Test Items and Word Class Affiliation in the Lexical Fields of Near Synonyms Used in the Present Study

\begin{tabular}{|c|c|c|c|c|c|}
\hline & $\begin{array}{l}3 \text { test items } \\
\text { involved }\end{array}$ & $\begin{array}{l}5 \text { test items } \\
\text { involved }\end{array}$ & $\begin{array}{c}6 \text { test items } \\
\text { involved }\end{array}$ & $\begin{array}{c}7 \text { test items } \\
\text { involved }\end{array}$ & Total \\
\hline English test & $\begin{array}{c}2 \\
\text { (1 field of nouns; } \\
1 \text { field of adjectives) }\end{array}$ & $\begin{array}{c}3 \\
\text { (1 field of nouns; } \\
2 \text { fields of verbs) }\end{array}$ & $\begin{array}{c}2 \\
\text { (1 field of nouns; } \\
1 \text { field of verbs) }\end{array}$ & $\begin{array}{c}1 \\
\text { (1 field of nouns) }\end{array}$ & 8 \\
\hline Swedish test & $\begin{array}{c}2 \\
\text { (1 field of verbs; } \\
1 \text { field of adjectives) }\end{array}$ & $\begin{array}{c}3 \\
\text { (2 fields of verbs; } \\
1 \text { field of adjectives) }\end{array}$ & $\begin{array}{c}2 \\
\text { (1 field of nouns; } \\
1 \text { field of verbs) }\end{array}$ & $\begin{array}{c}1 \\
\text { (1 field of verbs) }\end{array}$ & 8 \\
\hline
\end{tabular}

On the tests, the students were asked to pair up each item in a synonym set with its correct definition, each correct answer being awarded 1 point. While the English definitions were based on Longman dictionary of contemporary English (1987), the Swedish ones were taken from the same book as the near synonyms themselves. This is 
exemplified in (3) (lexical field number 2 consisting of 3 items) and (4) (lexical field number 7 consisting of 6 test items).

(3)

a) bright

b) fair

c) light

(4)

b) hop

c) jump

d) leap a) bound

_ (of the shade of a colour), (the opposite is dark)

(of a colour) strong, clear and easily seen, (the opposite is dull)

(of a colour) blond, used almost always about hair

to push oneself into the air or away from a surface by the force of one's legs, i.e. the general term for hoppa

to move in a light dancing way, with quick steps and jumps

to move quickly and suddenly upwards or forwards as if by jumping

1) to move along quickly from place to place by jumping movements, 2) to bounce back from a surface
e) skip
__ (of people) to jump on one leg
f) spring
to jump up in the air or over something

The students were also asked to give information about to what extent they were sure of the meanings they had assigned the various test items and if there were any test items that they did not know at all. This is exemplified in (5) with lexical field number 5 .

(5)
a) carpet
1) thick, usually woollen, comparatively small,
2) large warm woollen covering to wrap round oneself
b) mat
heavy woven often woollen material for covering
floors or stairs, i.e. the general term for matta
c) rug
a piece of rough strong material for covering part of a
floor 
Of the English words above, I have not seen the following word/s before:

I am not sure about the meaning/s of the following word/s:

I think I am sure about the meaning/s of the following word/s:

I am sure about the meaning/s of the following word/s:

In addition, the students were requested to evaluate the difficulty level of the tests. Here they could choose between 'very easy', 'easy', 'average', 'difficult' and 'very difficult'.

Finally, it is important to point out that the sizes of the two corpora used in the present investigation differ. The table below illustrates this difference.

Table 3. A Comparison between the Corpora as to the Frequency of the Test Items

\begin{tabular}{ccc}
\hline \multirow{2}{*}{ CORPUS } & \multicolumn{2}{c}{ LEXICAL FIELDS } \\
\cline { 2 - 3 } & \multicolumn{2}{c}{ OF NEAR SYNONYMS } \\
\hline & $\begin{array}{c}\text { Most } \\
\text { frequent } \\
\text { item }\end{array}$ & Total \\
\hline English corpus & $0.0168 \%$ & $0.0561 \%$ \\
Swedish corpus & $0.0074 \%$ & $0.0142 \%$ \\
\hline
\end{tabular}

As Table 3 shows, the total frequency of the items in focus is higher on the English test. The conclusion to be drawn, based on frequency alone, must be that the English synonym sets are somewhat easier than the Swedish sets.

\section{Results and Discussion}

Table 4 presents the informants' mean scores on the synsets tested.

Table 4. The Students’ Results

\begin{tabular}{|c|c|c|c|}
\hline STUDENTS & $\begin{array}{c}\text { LEXICAL FIELDS } \\
\text { OF NEAR SYNONOMS } \\
\text { MEAN } \\
\text { (40 ITEMS) }\end{array}$ & $\begin{array}{l}\text { STANDARD } \\
\text { DEVIATION }\end{array}$ & $\begin{array}{l}\text { STANDARDISED } \\
\text { SCORE }\end{array}$ \\
\hline $\begin{array}{l}\text { Native speaker } \\
\text { of English }\end{array}$ & 26.0 & - & - \\
\hline $\begin{array}{l}\text { Swedish students - } \\
\text { English test }\end{array}$ & 21.1 & 5.8781 & $\begin{array}{l}\text { highest score: } 1.8487 \\
\text { lowest score: }-1.5538\end{array}$ \\
\hline $\begin{array}{l}\text { Swedish students - } \\
\text { Swedish test }\end{array}$ & 31.5 & 7.0697 & $\begin{array}{l}\text { highest score: } 1.2070 \\
\text { lowest score: }-1.7634\end{array}$ \\
\hline
\end{tabular}

As anticipated, the native speaker achieved better results, although not considerably so, than the Swedish learners (26.0 versus a mean score of 21.1) who in turn did better in their mother tongue than in their L2 (31.5 versus 21.1). (It here needs to be pointed out that the native speaker of English appeared to be a low-achiever in almost all areas of the lexicon.) The difference in standard deviation indicates though that the Swedish test was no mean task for quite a few of the learners (see also the students' individual results in Tables 10 and 11). Some of the correct answers offered by the students must however of course be ascribed to the method of elimination whose effectiveness stands in direct relation to the number of items included in the synset, i.e. the fewer items the more likely it is to get it right, and to the number of items of which the informant is certain. However, the sometimes very finely tuned differences between the 
near synonyms in a synset certainly take away some of the advantage of here being able to use the method of elimination.

Table 5 shows the results of the participants' evaluation of the test's difficulty level.

Table 5. The Students' Evaluation of the Difficulty Level of the Test (ve=very easy, e=easy, av=average, $d=$ difficult, vd=very difficult)

\begin{tabular}{lccccc}
\hline \multicolumn{1}{c}{ STUDENTS } & \multicolumn{5}{c}{ LEXICAL FIELDS } \\
& OF NEAR SYNONYMS \\
\hline Native speaker & ve & e & av & d & vd \\
of English & - & $1 / 2$ & $1 / 2$ & - & - \\
Swedish students - & ve & e & av & d & vd \\
English test & - & - & 6 & 6 & 3 \\
Swedish students - & ve & e & av & d & vd \\
Swedish test & 1 & 6 & 6 & 1 & 1 \\
\hline
\end{tabular}

The Swedish students appear to have a comparatively good take on their knowledge of near synonyms, a majority of the L2 learners (9 students) indicating that the English test was either 'difficult' (6 subjects) or 'very difficult' (3 subjects) and that the Swedish test items were either 'easy' (6 informants) or even 'very easy' ( 1 informant). The native speaker, on the other hand, appears to have overestimated his knowledge, indicating that the test was somewhere between 'easy' and 'average'.

Tables 6 (English synsets) and 7 (Swedish synsets) present the L2 learners' results on each of the synonym sets tested. The sets are presented according to 1) the number of items involved, starting with the synsets with the fewest number of members, and 2) the total number of correct answers, beginning with the set that received the highest score. On the English test, this means that the synonym sets bright-light-fair and carpet-rug-mat involving only three test items each are presented first, bright-light-fair preceding carpet-rug-mat because it received more correct answers of the two (38 out 45 points versus 37 out of 48 points). These two fields are then followed by synsets consisting of 5 near synonyms: first solicitor-lawyer-attorney-barrister-advocate, which received 49 out of 75 points, second claim-maintain-stateassert-allege (38 out of 75 points) and third tremble-shiver-shudder-quiver-quaver (26 out of 75 points) and so on. Since both tests include the same number of synsets and items within each set, the Swedish test results are presented in exactly the same fashion. Also, except for three items on the English test part (fair belonging to lexical field number 2 and disorder and complaint both belonging to synset number 1) and two items on the Swedish test part (vred (=furious) (lexical field number 5) and tät (=rolling in money) (synset number 3)) which all have more than one meaning and for which it therefore was impossible to determine frequency and thus placed last, the synonyms within each synset are presented according to frequency, based on the BNC and Språkbanken respectively, starting with the most common item. In lexical field number 3 on the English test, for example, the most common item was accident, followed by disaster, catastrophe, misfortune, calamity and, finally, mishap. Lastly, the items indicated in red were found on West's service list (1953), a list including 2,000 of the most common words in the English language. With a few exceptions (carpet, solicitor and spring), these items appear to tally quite well with the relative frequencies obtained from the BNC. No such corresponding list was found for Swedish vocabulary.

Table 6. The Students' Results on and Evaluation of the English Test on Lexical Fields of Near Synonyms (LF=Lexical Field) (highest score indicated in grey)

\begin{tabular}{clcccc}
\hline LF & WORD & SURE & THINK SURE & NOT SURE & NOT SEEN \\
\hline LF2 & bright (13) & $12(1)$ & $3(1)$ & & \\
$(38 / 45)$ & light (13) & $12(2)$ & 3 & $2(2)$ & \\
& fair* (12) & $9(2)$ & $4(1)$ & & \\
& & & & & \\
LF5 & carpet (14) & 3 & 8 & $2(1)$ & $3(2)$ \\
$(37 / 45)$ & rug (12) & 1 & $9(1)$ & $4(3)$ & $3(1)$ \\
\hline LF4 & solicitor (11) & 4 & $3(1)$ & $3(3)$ & \\
\hline
\end{tabular}




\begin{tabular}{|c|c|c|c|c|c|}
\hline \multirow[t]{4}{*}{$(49 / 75)$} & lawyer (11) & $5(2)$ & 5 & $2(2)$ & \multirow[b]{3}{*}{1} \\
\hline & attorney (7) & $4(2)$ & $6(3)$ & $2(1)$ & \\
\hline & barrister (12) & 3 & $5(1)$ & $4(3)$ & \\
\hline & advocate (8) & $3(1)$ & $3(2)$ & $4(2)$ & $2(1)$ \\
\hline \multirow{5}{*}{$\begin{array}{c}\text { LF6 } \\
(38 / 75)\end{array}$} & claim (4) & $3(2)$ & $6(4)$ & 3 & \multirow{6}{*}{$2(1)$} \\
\hline & maintain (14) & 2 & 6 & $4(3)$ & \\
\hline & state (10) & $3(1)$ & $6(1)$ & $3(1)$ & \\
\hline & assert (4) & $1(1)$ & $4(3)$ & $8(2)$ & \\
\hline & allege (6) & 3 & $3(2)$ & $7(2)$ & \\
\hline \multirow{5}{*}{$\begin{array}{c}\text { LF8 } \\
(26 / 75)\end{array}$} & tremble (6) & $2(2)$ & $6(2)$ & $4(2)$ & \\
\hline & shiver (10) & $2(1)$ & $8(2)$ & $2(2)$ & 1 \\
\hline & shudder (3) & $1(1)$ & $5(4)$ & $3(1)$ & $4(1)$ \\
\hline & quiver (4) & $1(1)$ & $3(3)$ & $3(1)$ & $6(1)$ \\
\hline & quaver (3) & & $1(1)$ & $4(2)$ & $10(1)$ \\
\hline \multirow{6}{*}{$\begin{array}{c}\text { LF3 } \\
(61 / 90)\end{array}$} & accident (15) & 7 & 4 & $2(2)$ & \\
\hline & disaster (8) & $6(3)$ & $5(1)$ & $2(1)$ & \\
\hline & catastrophe (10) & $7(2)$ & $4(1)$ & $2(2)$ & \\
\hline & misfortune (13) & 4 & $6(2)$ & $2(2)$ & \\
\hline & calamity (5) & & $3(2)$ & 1 & $11(4)$ \\
\hline & mishap (10) & 2 & $4(1)$ & $1(1)$ & $7(3)$ \\
\hline & jump (13) & 7 & 5 & 1 & \multirow{6}{*}{$\begin{array}{c}2 \\
2(1) \\
2 \\
6(2) \\
3(1)\end{array}$} \\
\hline & leap (6) & 2 & $5(4)$ & $5(2)$ & \\
\hline LF7 & hop (5) & 1 & $3(3)$ & $8(3)$ & \\
\hline \multirow[t]{3}{*}{$(39 / 90)$} & skip (9) & 3 & 4 & $5(1)$ & \\
\hline & bound (3) & & $1(1)$ & $7(1)$ & \\
\hline & spring (3) & & $4(3)$ & $8(1)$ & \\
\hline \multirow{8}{*}{$\begin{array}{c}\text { LF1 } \\
(29 / 105)\end{array}$} & disease (3) & $6(5)$ & $3(3)$ & 1 & \\
\hline & illness (2) & $3(3)$ & $8(7)$ & 1 & \\
\hline & sickness (6) & $3(2)$ & $7(4)$ & $1(1)$ & \\
\hline & infirmity (2) & & & $5(1)$ & $10(1)$ \\
\hline & ailment (4) & & $1(1)$ & $2(2)$ & $11(1)$ \\
\hline & disorder* (9) & $3(1)$ & $6(3)$ & $3(2)$ & \multirow{3}{*}{1} \\
\hline & complaint* (3) & $1(1)$ & $5(3)$ & 4 & \\
\hline & TOTAL: 317/690 & & & & \\
\hline
\end{tabular}


Table 7. The Students' Results on and Evaluation of the Swedish Test on Lexical Fields of Near Synonyms (LF=Lexical Field) (highest score indicated in grey)

\begin{tabular}{|c|c|c|c|c|c|c|}
\hline \multirow[t]{2}{*}{ LF } & \multirow[t]{2}{*}{ WORD } & & \multirow[t]{2}{*}{ SURE } & \multirow{2}{*}{$\begin{array}{c}\mathrm{T} \\
\text { SURE }\end{array}$} & \multirow{2}{*}{$\begin{array}{l}\text { NOT } \\
\text { SURE }\end{array}$} & \multirow{2}{*}{$\begin{array}{l}\text { NOT } \\
\text { SEEN }\end{array}$} \\
\hline & & & & & & \\
\hline \multirow{3}{*}{$\begin{array}{c}\text { LF8 } \\
(39 / 45)\end{array}$} & lipa (13) & (=blubber) & $11(2)$ & 3 & & \\
\hline & snyfta (12) & $(=$ sob $)$ & $12(3)$ & 2 & & \\
\hline & snörvla (14) & (=snuffle) & $12(1)$ & 2 & & \\
\hline \multirow{3}{*}{$\begin{array}{c}\text { LF5 } \\
(29 / 45)\end{array}$} & förnärmad (9) & (=offended) & $4(1)$ & $6(3)$ & $1(1)$ & \\
\hline & förtretad (9) & (=annoyed) & $3(1)$ & $3(1)$ & $3(2)$ & $3(1)$ \\
\hline & vred* (11) & (=furious) & $5(1)$ & $4(1)$ & $1(1)$ & $1(1)$ \\
\hline \multirow{5}{*}{$\begin{array}{c}\text { LF4 } \\
(71 / 75)\end{array}$} & snegla (14) & (=glance) & 10 & $3(1)$ & & \\
\hline & kisa (15) & (=peer (e.g. bright light)) & 9 & 4 & & \\
\hline & glo (14) & (=stare) & 10 & $3(1)$ & & \\
\hline & plira (14) & (=peer) & 4 & 3 & $2(2)$ & $4(4)$ \\
\hline & blänga (14) & (=glare) & 10 & $3(1)$ & & \\
\hline \multirow{5}{*}{$\begin{array}{c}\text { LF7 } \\
(67 / 75)\end{array}$} & dugga (14) & (=drizzle) & 11 & 2 & & \\
\hline & skvätta (13) & (=splash) & 10 & $2(1)$ & & \\
\hline & strila (14) & (=raining gently) & 9 & 3 & & $1(1)$ \\
\hline & skvala (13) & (=pour) & 6 & $4(1)$ & & $3(3)$ \\
\hline & hällregna (13) & (=raining cats and dogs) & $8(1)$ & 4 & & $2(1)$ \\
\hline \multirow{5}{*}{$\begin{array}{c}\text { LF3 } \\
(48 / 75)\end{array}$} & välmående (11) & (=flourishing) & 4 & $6(4)$ & $1(1)$ & \\
\hline & förmögen (6) & (=wealthy) & $5(2)$ & $6(5)$ & & \\
\hline & stormrik (11) & (=immensely rich) & $7(1)$ & $4(1)$ & & \\
\hline & burgen (9) & (=from a wealthy family) & 2 & $2(2)$ & $1(1)$ & $8(5)$ \\
\hline & tät* (11) & (=rolling in money (slang)) & $7(1)$ & 3 & & 1 \\
\hline \multirow{6}{*}{$\begin{array}{c}\text { LF6 } \\
(78 / 90)\end{array}$} & fnissa (11) & (=giggle) & 8 & $5(3)$ & & \\
\hline & flina (14) & (=sneer) & 8 & $5(1)$ & & \\
\hline & fnittra (11) & (=giggle nervously) & 8 & $5(3)$ & & \\
\hline & flamsa (14) & (=fool around and laugh) & $6(1)$ & 7 & & \\
\hline & flabba (13) & (=guffaw) & $5(1)$ & $6(1)$ & $2(2)$ & \\
\hline & skrocka (15) & (=chuckle) & 5 & 6 & $2(2)$ & \\
\hline \multirow{4}{*}{$\begin{array}{c}\text { LF2 } \\
(72 / 90)\end{array}$} & dam (12) & (=lady) & $10(2)$ & $4(1)$ & & \\
\hline & $\operatorname{tant}(13)$ & (=nice lady; auntie) & $10(2)$ & 4 & & \\
\hline & donna (12) & (=bird, broad) & $8(2)$ & $4(1)$ & $2(2)$ & \\
\hline & kär(r)ing (12) & (=hag; old woman; missus) & $8(1)$ & $5(1)$ & & \\
\hline
\end{tabular}




\begin{tabular}{|c|c|c|c|c|c|c|}
\hline \multirow{2}{*}{\multicolumn{2}{|c|}{$\begin{array}{l}\text { fruntimmer (11) } \\
\text { gumma (12) }\end{array}$}} & (=jokingly or depreciatory) & $8(3)$ & $5(1)$ & & \\
\hline & & (=old woman; missus) & $10(2)$ & $4(1)$ & & \\
\hline \multirow{7}{*}{$\begin{array}{c}\text { LF1 } \\
(68 / 105)\end{array}$} & diskutera (11) & (=discuss) & $8(2)$ & $4(1)$ & & \\
\hline & argumentera (12) & (=argue (pro or con)) & $8(2)$ & $4(1)$ & & \\
\hline & konversera (10) & (=converse) & $6(3)$ & $5(1)$ & & \multirow{5}{*}{$4(3)$} \\
\hline & babbla (6) & (=babble) & $8(3)$ & $3(2)$ & 1 & \\
\hline & orera (8) & (=speechify) & 1 & $5(3)$ & $3(3)$ & \\
\hline & tjattra (12) & (=chatter) & 6 & 4 & $2(1)$ & \\
\hline & samspråka (9) & (=have a chat, talk) & $5(1)$ & $5(3)$ & $2(2)$ & \\
\hline
\end{tabular}

TOTAL: 472/690

As already indicated by the mean scores presented in Table 4, the Swedish learners displayed considerably more confidence with near synonyms in their L1 than in their L2. This is shown in several ways in Tables 6 and 7. For example, whereas a majority of the students indicated complete unfamiliarity with only 2 of the Swedish test items (förtretad (=annoyed) and burgen (=from a wealthy family) (column NOT SEEN and indicated in grey)), as many as 7 of the English near synonyms were equally unfamiliar to a majority of the learners. These are shudder, quiver and quaver, all of which belong to lexical field number 8 , thus unsurprisingly rendering this set the least best known of those containing 5 items, calamity and mishap (both belonging to lexical field number 7), and infirmity and ailment (members of synset number 1). Similarly, while for an overwhelming majority of the Swedish test items most of the students indicated that they were sure of the definition chosen, this only occurred with 7 of the English test items: bright, light and fair (lexical field number 2), solicitor (synonym set number 4), accident and catastrophe (synset number 3) and jump (set number 7), more students thus indicating less degree of certainty (column THINK SURE) (very few on the Swedish test) or indicating that they were not sure at all about the definition they had chosen (column NOT SURE) (none on the Swedish test). In fact, the results seen here with the English test items appear to be directly linked to the items' frequencies, i.e. the degree of certainty displayed by the subjects of having chosen the correct definition stands in direct relation to the frequency of the item in question. If the synonym sets in Table 6 are considered, this holds true for bright in lexical field number 2 (with the reservation that the frequency for fair could not be ascertained), accident in synonym set number 3, carpet in synset number 5 and jump in set number 7, i.e. in $50 \%$ of the cases. As discussed previously, the effect of frequency was also noticed in Schmitt \& Dunham (1999) where it was shown that non-native speakers were almost as good as native speakers at picking out the most frequent word in a synonym set. The positive effect of frequency was also confirmed in Haastrup \& Henriksen (2000) also discussed earlier. With the Swedish test items, on the other hand, of which the subjects were more certain, there was also less sensitivity to frequency.

Furthermore, the effect of frequency seen with the English test items will become even more visible if the near synonyms are compared on an individual basis irrespective of which synset they belong to, as seen in Table 8. (Table 9 presents the Swedish words in the same manner.) The near synonym accident, for instance, is the second most common of all the items in the English synsets (see first column LEXICAL FIELD (FREQUENCY)). Hence, of the 21 English items for which most of the students gave the right definitions (from accident (15 points) down to and including disaster (8 points)), 15 are also among the 20 most frequent items. This means that of the 19 items for which a majority of the students did not succeed in offering the right definitions (from attorney ( 7 points) to infirmity (2 points)), only 5 are among the 20 most frequent items. The less pronounced effect of frequency in the students' L1, on the other hand, makes the comparatively frequent items more evenly distributed (see Table 9).

Moreover, it is not only within synsets that the frequency effect appears to be at work. If synonym sets with the same number of items are compared, it can be seen that those for which the total frequency is the highest are consistently also those that the students do best with, lexical field 4, containing 5 near synonyms, for instance, receiving more points than lexical fields 6 and 8 (49 out of 75 as compared to 38 and 26).

Finally, it is also interesting to note that for on the one hand those 3 synsets that involved 5 items each (lexical fields 4 , 6 and 8 ) and on the other hand for those 2 synsets that incorporated 6 near synonyms each (lexical fields 3 and 7 ), the 
subjects did, in both cases, better with the nouns than with the verbs. This tallies with the fact that nouns are generally considered to be easier to deal with than verbs.

Table 8. The Near Synonyms on the English Test Presented Individually Disregarding Synset Membership

\begin{tabular}{cl}
\hline LEXICAL FIELD & \multicolumn{1}{c}{ WORD } \\
(FREQUENCY) & \\
\hline LF3 (2) & accident (15) \\
LF5 (9) & carpet (14) \\
LF6 (12) & maintain (14) \\
LF2 (3) & bright (13) \\
LF2 (4) & light (13) \\
LF3 (20) & misfortune (13) \\
LF7 (21) & jump (13) \\
LF2 (38) & fair (12) \\
LF5 (13) & rug (12) \\
LF4 (15) & barrister (12) \\
LF5 (16) & mat (11) \\
LF4 (6) & solicitor (11) \\
LF4 (8) & lawyer (11) \\
LF6 (17) & state (10) \\
LF8 (33) & shiver (10) \\
LF3 (19) & catastrophe (10) \\
LF3 (24) & mishap (10) \\
LF7 (31) & skip (9) \\
LF1 (40) & disorder (9) \\
LF4 (18) & advocate (8) \\
LF3 (7) & disaster (8) \\
LF4 (14) & attorney (7) \\
LF6 (28) & allege (6) \\
LF8 (26) & tremble (6) \\
LF7 (25) & leap (6) \\
LF1 (11) & sickness (6) \\
LF3 (23) & calamity (5) \\
LF7 (30) & hop (5) \\
LF6 (10) & claim (4) \\
LF6 (22) & assert (4) \\
LF8 (36) & quiver (4) \\
LF1 (29) & ailment (4) \\
LF8 (34) & shudder (3) \\
LF8 (37) & quaver (3) \\
LF7 (32) & bound (3) \\
LF7 (35) & spring (3) \\
LF1 (1) & disease (3) \\
LF1 (39) & complaint (3) \\
\hline & illness (2) \\
infirmity (2) \\
\hline
\end{tabular}


Table 9. The Near Synonyms on the Swedish Test Presented Individually Disregarding Synset Membership

\begin{tabular}{|c|c|c|}
\hline $\begin{array}{l}\text { LEXICAL FIELD } \\
\text { (FREQUENCY) }\end{array}$ & & VORD \\
\hline LF4 (10) & kisa (15) & (=peer (e.g. bright light)) \\
\hline LF6 (35) & skrocka (15) & (=chuckle) \\
\hline LF8 (38) & snörvla (14) & (=snuffle) \\
\hline LF4 (7) & snegla (14) & (=glance) \\
\hline LF4 (11) & glo (14) & (=stare) \\
\hline LF4 (29) & plira (14) & (=peer) \\
\hline LF4 (36) & blänga (14) & (=glare) \\
\hline LF7 (18) & dugga (14) & (=drizzle) \\
\hline LF7 (24) & strila (14) & (=raining gently) \\
\hline LF6 (16) & flina (14) & (=sneer) \\
\hline LF6 (27) & flamsa (14) & (=fool around and laugh) \\
\hline LF8 (25) & lipa (13) & (=blubber) \\
\hline LF7 (19) & skvätta (13) & (=splash) \\
\hline LF7 (34) & skvala (13) & (=pour) \\
\hline LF7 (37) & hällregna (13) & (=raining cats and dogs) \\
\hline LF6 (31) & flabba (13) & (=guffaw) \\
\hline LF2 (4) & $\operatorname{tant}(13)$ & (=nice lady; auntie) \\
\hline LF8 (26) & snyfta (12) & (=sob) \\
\hline LF2 (2) & $\operatorname{dam}(12)$ & (=lady) \\
\hline LF2 (6) & donna (12) & (=bird, broad) \\
\hline LF2 (9) & kär(r)ing (12) & (=hag; old woman; missus) \\
\hline LF2 (13) & gumma (12) & (=old woman; missus) \\
\hline LF1 (5) & argumentera (12) & (=argue (pro or con)) \\
\hline LF1 (30) & tjattra (12) & (=chatter) \\
\hline LF5 (40) & vred (11) & (=furious) \\
\hline LF3 (3) & välmående (11) & (=flourishing) \\
\hline LF3 (20) & stormrik (11) & (=immensely rich) \\
\hline LF3 (39) & tät (11) & (=rolling in money (slang)) \\
\hline LF6 (14) & fnissa (11) & (=giggle) \\
\hline LF6 (23) & fnittra (11) & (=giggle nervously) \\
\hline LF2 (12) & fruntimmer (11) & (=jokingly or depreciatorily) \\
\hline LF1 (1) & diskutera (11) & (=discuss) \\
\hline LF1 (15) & konversera (10) & (=converse) \\
\hline LF5 (21) & förnärmad (9) & (=offended) \\
\hline LF5 (32) & förtretad (9) & (=annoyed) \\
\hline LF3 (28) & burgen (9) & (=from a wealthy family) \\
\hline LF1 (33) & samspråka (9) & (=have a chat, talk) \\
\hline LF1 (22) & orera (8) & (=speechify) \\
\hline LF3 (8) & förmögen (6) & (=wealthy) \\
\hline LF1 (17) & babbla (6) & (=babble) \\
\hline
\end{tabular}

\section{Individual L1 and L2 Knowledge of Lexical Fields of Near Synonyms}

Tables 10 and 11 below show the students' individual scores on the English and Swedish test respectively. For 12 of the 15 students there is a clear correlation between their mastery of near synonyms in their L1 and in the language they are trying to learn. Whereas Students 2, 5, 8, 9, 11 and 14 (indicated in orange) achieved scores above the mean in both languages, Students 3, 4, 6, 10, 13 and 15 (highlighted in yellow) achieved scores below the mean in both languages. This result shows clearly that this type of L2 vocabulary knowledge is affected by your L1 mastery. 
It is also worth pointing out that there were Swedish students who received scores that were higher than the native speaker's. It can be seen that 3 subjects (Students 2, 5 and 14) outperformed the native speaker who received 26 points out of 40. Still another subject, Student 9, came close, achieving a total score of 25. In Schmitt \& Dunham's article 'Exploring native and non-native intuitions of word frequency' (1999) presented earlier, it was noticed that L2 learners are often able to assess the frequency (both relative and absolute) of near synonyms almost as well as native speakers. As previously, the positive effect of frequency was also seen in the present study, both the frequency of the most common item in a synonym set and the total frequency of a synset in relation to frequencies of other synsets. Considering the fact that the definitions of the near synonyms often offered vital information as to their commonality (e.g. which of the items is the superordinate), it is very likely that the subjects' sensitivity to frequency enabled some of the more advanced Swedish students to outperform the relatively low-achieving native informant.

Table 10. The Students’ Individual

Scores on Lexical Fields of Near Synonyms (English test).

\begin{tabular}{lc}
\hline & $\begin{array}{c}\text { SCORE FOR } \\
\text { LEXICAL FIELDS } \\
\text { STUDENT } \\
\text { NEAR SYNONYMS } \\
\text { ENGLISH TEST } \\
\text { (40 ITEMS) }\end{array}$ \\
\hline STUDENT 14 & 32 \\
STUDENT 5 & 30 \\
STUDENT 2 & 29 \\
STUDENT 9 & 25 \\
STUDENT 8 & 23 \\
STUDENT 11 & 22 \\
\hline STUDENT 7 & 21 \\
\hline STUDENT 15 & 21 \\
STUDENT 3 & 20 \\
\hline STUDENT 1 & 18 \\
\hline STUDENT 13 & 18 \\
STUDENT 10 & 16 \\
\hline STUDENT 6 & 15 \\
\hline STUDENT 12 & 15 \\
\hline STUDENT 4 & 12 \\
\hline
\end{tabular}

Table 11. The Students' Individual

Scores on Lexical Fields of Near Synonyms (Swedish test).

\begin{tabular}{|c|c|}
\hline STUDENT & $\begin{array}{c}\text { SCORE FOR } \\
\text { LEXICAL FIELDS } \\
\text { NEAR SYNONYMS } \\
\text { SWEDISH TEST } \\
\text { (40 ITEMS) }\end{array}$ \\
\hline $\begin{array}{l}\text { STUDENT } 11 \\
\text { STUDENT } 2\end{array}$ & 40 \\
\hline $\begin{array}{l}\text { STUDENT } 9 \\
\text { STUDENT } 14\end{array}$ & 38 \\
\hline STUDENT 8 & 37 \\
\hline STUDENT 5 & 36 \\
\hline STUDENT 12 & 35 \\
\hline STUDENT 7 & 34 \\
\hline STUDENT 1 & 32 \\
\hline STUDENT 6 & 32 \\
\hline STUDENT 3 & 24 \\
\hline STUDENT 13 & 24 \\
\hline STUDENT 15 & 23 \\
\hline STUDENT 4 & 22 \\
\hline STUDENT 10 & 19 \\
\hline
\end{tabular}

\section{Pedagogical Implications of the Results}

As described in Section 1.1, creating links between words is a difficult and time-consuming task. This is substantiated even further by the fact that even advanced students such as a majority of the ones included in the present investigation display a poor knowledge of near synonyms. In order to promote network building, teachers therefore need to make use of all the pedagogical tools available. Since frequency, both the relative frequencies of the near synonyms and total frequencies of the synonym sets as a whole, proved to have a positive effect on the students' mastery, this appears to be the most useful tool, Commonality could therefore certainly be used to guide teachers in their selection of items to be part of the teaching syllabus. Having in mind that the frequency of a near synonym often tallies with its degree of generality, i.e. whether the term is a superordinate or a hyponym with increased specificity, teachers could start with the most frequent item (i.e. very often the superordinate) of the more frequent synonym sets and, only after these have been acquired, move on to more infrequent items within the same synonym set (i.e. hyponyms), the more specialised items of infrequent synsets being the very last items on the teaching syllabus. 
Unfortunately, for synsets, "few indeed are the suggestions in the ESL literature on how to impart sensitivity to the distinctions between closely related lexical items" (Martin, 1984:135). Most researchers appear to agree though that items should be presented in a contextualised form as exemplified in (4) below, where learners were instructed to pick the correct alternative to fit the context (Channell, 1981). (See also Wallace Robinett (1978), Mackay (1980) and Shioji (1982) for more examples of the same kind.)

(4) As we reached the top of the hill a view stretched out before us.

(alternatives: good-looking, handsome, beautiful)

As pointed out before, however, some researchers have produced results that indicate that near synonyms should not be presented together at all. Waring (1997:270), for example, suggests that a thematic approach to near synonyms be more useful than a semantic one. These conflicting results may suggest that what method to use depends largely on the preference of each individual student. More research in this area is therefore needed.

\section{References}

Aitchison, J. (1994). Words in the mind. An introduction to the mental lexicon. (2nd ed.). Oxford: Blackwell.

Albrechtsen, D., Haastrup, K., \& Henriksen, B. (2008). Vocabulary and writing in a first and second language: Processes and development. New York: Palgrave Macmillan. http://dx.doi.org/10.1057/9780230593404

Arnaud, P. J. L. (1989). Estimations subjectives des frequencies des mots. Cahiers de Lexicologie, 54, 69-81.

Backman, J. (1978). Subjective structures in linguistic recurrence. Educational Resources Information Center (ERIC) documents ED180195.

Channell, J. (1981). Applying semantic theory to vocabulary teaching. ELT Journal, 35, 115-122. http://dx.doi.org/10.1093/elt/XXXV.2.115

Cohen, A. D., \& Aphek, E. (1981). Easifying second language learning. Studies in Second Language Acquisition, 3(2), 221-236. http://dx.doi.org/10.1017/S0272263100004198

Haastrup, K., \& Henriksen, B. (2000). Vocabulary acquisition: acquiring depth of knowledge through network building. International Journal of Applied Linguistics, 10(2), 221-239. http://dx.doi.org/10.1111/j.1473-4192.2000.tb00149.x

Hallström, A., \& Östberg, U. (2003). De rätta orden: Svenska betydelsefält. Lund: Studentlitteratur.

Hargevik, S., \& Stevens, M. (1978). English synonyms and false friends. Lund: Liber Läromedel.

Holmegaard, M. (2000). Språkmedvetenhet och ordinlärning-lärare och inlärare reflekterar kring en betydelsefältsövning i svenska som andraspråk. In H. Åhl (ed.) Svenskan i tiden: verklighet och visioner (pp. 109-120). Stockholm: HLS.

Longman dictionary of contemporary English. (1987). Harlow: Longman.

Mackay, D. (1966). To end ambiguous sentences. Perception and Psychophysics, 1, 426-436. http://dx.doi.org/10.3758/BF03215819

Martin, M. (1984). Advanced vocabulary teaching: The problem of synonyms. The Modern Language Journal, 68(2), 130-137.

McGeoch, A., \& McDonald, W. T. (1931). Meaningful relation and retroactive inhibition. American Journal of Psychology, 43, 579-588. http://dx.doi.org/10.2307/1415159

Meara, P. (1978). Learners’ word associations in French. Interlanguage Studies Bulletin Utrecht, 3, 192-211.

Murphy, G. L. (2004). The big book of concepts. Cambridge, MA: MIT Press.

Nagy, W. E. (1989). Teaching vocabulary to improve reading comprehension. Newark: International Reading Association.

Namei, S. (2002). The bilingual lexicon from a developmental perspective: A word association study of Persian-Swedish bilinguals. Centre for Research on Bilingualism: Stockholm University. http://dx.doi.org/10.1111/j.1473-4192.2004.00070.x

Namei, S. (2004). Bilingual lexical development: A Persian-Swedish word association study. International Journal of Applied Linguistics, 14(3), 363-388. 
Piper, T. H., \& Leicester, P. F. (1980). Word association behavior as an indicator of English language proficiency. Educational Resources Information Center (ERIC) documents ED227651.

Read, J. (1993). The development of a new measure of L2 vocabulary knowledge. Language Testing, 10, 355-371. http://dx.doi.org/10.1177/026553229301000308

Richards, J. C. (1974). Word lists: Problems and prospects. RELC Journal, 5, 69-84. http://dx.doi.org/10.1177/003368827400500207

Ringeling, T. (1984). Subjective estimations as a useful alternative to word frequency counts. Interlanguage Studies Bulletin, 8, 59-69.

Rudzka, B., Channel, J., Pudseys, Y., \& Ostyn, P. (1981). The words you need. London: McMillan.

Schmitt, N., \& Dunham, B. (1999). Exploring native and non-native intuitions of word frequency. Second Language Research, 15(4), 389-411. http://dx.doi.org/10.1191/026765899669633186

Shioji, J. (1982). Affirmative approaches to vocabulary development. TESOL Convention, Honolulu, HI.

Singleton, D. (1999). Exploring the second language mental lexicon. Cambridge: Cambridge University Press. http://dx.doi.org/10.1017/CBO9781139524636

Söderman, T. (1993). Word associations of foreign language learners and native speakers: The phenomenon of a shift in response type and its relevance for lexical development. In H. Ringbom (ed.) Near native proficiency in English. Åbo: Åbo Akademi.

Tinkham, T. (1993). The effect of semantic clustering on the learning of second language vocabulary. System, 21(3), 371-380. http://dx.doi.org/10.1016/0346-251X(93)90027-E

Wallace Robinett, B. (1978). Teaching English to speakers of other languages. New York: McGraw-Hill.

Waring, R. (1997). The negative effects of learning words in semantic sets: A replication. System, 25(2), 261-274. http://dx.doi.org/10.1016/S0346-251X(97)00013-4

West, M. (1953). A general service list of English words. London: Longman.

Wilks, C., \& Meara, P. (2002). Untangling word webs: Graph theory and the notion of density in second language word association networks. Second Language Research, 18, 303-324. http://dx.doi.org/10.1191/0267658302sr203oa

Wolter, B. (2001). Comparing the L1 and L2 mental lexicon: A depth of individual word knowledge model. Studies in Second Language Acquisition, 23, 41-69. http://dx.doi.org/10.1017/S0272263101001024 